DOI: $10.17516 / 1997-1370-0761$

УДК 159.99

\title{
Economic Behaviour Strategies \\ of the Northern Small-Numbered Indigenous Peoples and their Impact on Subjective Well-Being
}

\author{
Ekaterina V.Zabelina ${ }^{a}$, Svetlana A. Kurnosova ${ }^{a}$, \\ Natalya P. Koptseva ${ }^{b}$, Vladimir S. Luzan ${ }^{\mathrm{b}}$ \\ and Ksenia E. Shchukina ${ }^{a *}$ \\ ${ }^{a}$ Chelyabinsk State University \\ Chelyabinsk, Russian Federation \\ ${ }^{b}$ Siberian Federal University \\ Krasnoyarsk, Russian Federation
}

Received 26.03.2021, received in revised form 16.04.2021, accepted 21.05.2021

\begin{abstract}
Russian academic literature is characterised by a lack of data on the features of the economic behaviour of representatives of the indigenous small-numbered peoples of the North, Siberia, and the Far East of the Russian Federation (hereinafter referred to as ISNPN, the indigenous minorities). Nevertheless, economic, environmental, geopolitical, and social changes in the Arctic region of Russia make it extremely relevant to study the process of transformation of the economic behaviour of these peoples.

The article presents the results of a study of the main strategies of economic behaviour of the indigenous peoples (Nenets, Dolgans, Itelmens, Koryaks, Nivkhs, Chukchi, and Evens) and the impact of these strategies on their subjective well-being. In this way, factor analysis made it possible to identify 4 factors that can be interpreted as independent strategies of the economic behaviour of the ISNPN: the saving strategy based on financial knowledge and activity; the strategy of independent financial achievements; the restrictive strategy in the economic sphere based on rationality and independence, and the strategy of hired labour.

The article notes that the regression analysis demonstrated particular importance of the saving strategy based on financial knowledge and activity, which makes the greatest contribution to increasing subjective well-being of the indigenous peoples. It has been noted that a peculiarity of the economic behaviour of the ISNPN representatives is the predominance of an orientation towards savings and rationality in almost all identified strategies.

The results of the study are summarised in the conclusion, and a deduction about the significant role of increasing financial literacy in improving subjective well-being of indigenous minorities is drawn.
\end{abstract}

\footnotetext{
(c) Siberian Federal University. All rights reserved

* Corresponding author E-mail address: katya_k@mail.ru,ksa0308@mail.ru, decanka@mail.ru, vladimir_luzan@list.ru, Shchks4@mail.ru

ORCID: 0000-0003-3910-7991 (Koptseva)
} 
Keywords: economic behaviour, indigenous small-numbered peoples, economic attitudes, subjective well-being, economic strategies.

The study was carried out with the financial support of the Russian Federal Property Fund in the framework of the scientific project No. 19-013-00394 «Transformation of the economic behaviour of the indigenous small-numbered peoples of the North living in the Arctic zone of the Russian Federation in the context of globalization».

Research area: culturology.

Citation: Zabelina, E.V., Kurnosova, S.A., Koptseva, N.P., Luzan, V.S., Shchukina, K.E. (2021). Economic behaviour strategies of the Northern small-numbered indigenous peoples and their impact on the subjective well-being. J. Sib. Fed. Univ. Humanit. Soc. Sci., 14(6), 797-809. DOI: 10.17516/1997$1370-0761$.

\title{
Стратегии экономического поведения коренных малочисленных народов Севера и их влияние на субъективное благополучие
}

\author{
Е.В. Забелина ${ }^{a}$, С.А. Курносова ${ }^{a}$, \\ Н.П. Копцеваб , В.С. Лузанб , К.Е. Щукина \\ ${ }^{а}$ Челябинский государственный университет \\ Российская Федераиия, Челябинск \\ ${ }^{6}$ Сибирский федеральный университет \\ Российская Федерачия, Красноярск
}

\begin{abstract}
Аннотация. В отечественной научно-исследовательской литературе необходимо зафиксировать определенный дефицит данных об особенностях экономического поведения представителей коренных малочисленных народов Севера, Сибири и Дальнего Востока Российской Федерации (далее-КМНС, коренные малочисленные народы). Тем не менее экономические, экологические, геополитические и социальные изменения в Арктическом регионе России делают крайне актуальным изучение процесса трансформации экономического поведения данных народов.

В статье представлены результаты исследования основных стратегий экономического поведения представителей КМНС (ненцы, долганы, ительмены, коряки, нивхи, чукчи, эвены) и влияние данных стратегий на их субъективное благополучие. Так, факторный анализ позволил выделить четыре фактора, которые могут быть интерпретированы как самостоятельные стратегии экономического поведения КМНС: стратегия сбережений на основе финансовых знаний и активности; стратегия самостоятельных финансовых достижений; ограничительная стратегия в экономической сфере, основанная на рациональности и самостоятельности; стратегия наемной работы.

В статье отмечается, что регрессионный анализ показал особую значимость стратегии сбережений на основе финансовых знаний и активности, которая вносит наибольший вклад в повышение субъективного благополучия представителей коренных малочисленных народов. Отмечено, что особенностью экономического
\end{abstract}

$$
-798-
$$


поведения представителей КМНС является преобладание ориентации на сбережения и рациональность практически во всех установленных стратегиях.

В заключении обобщены результаты исследования и сделан вывод о значимой роли повышения финансовой грамотности в увеличении субъективного благополучия представителей коренных малочисленных народов.

Ключевые слова: экономическое поведение, коренные малочисленные народы, экономические аттитюды, субъективное благополучие, экономические стратегии.

Исследование выполнено при финансовой поддержке РФФИ в рамках научного проекта № 19-013-00394 «Трансформация экономического поведения коренных малочисленных народов Севера, проживающих на территории Арктической зоны Российской Федерации в условиях глобализации».

Научная специальность: 24.00.00 - культурология.

\section{Введение}

Включение Арктики в глобальную повестку дня, возрастание ее геополитической и экономической роли в мире обращают внимание различных субъектов (политики, промышленники, военные, исследователи и т. д.) на населяющие ее народы. В первую очередь, это обусловлено интенсивным развитием добывающей экономики в Арктике и становлением данного региона новым геополитическим узлом напряженности между ведущими державами (Россия, Китай, США, Канада и др.). В связи с этим изучение в том числе экономического поведения коренных малочисленных народов, проживающих на данной территории Российской Федерации и ведущих традиционный образ жизни, становится чрезвычайно актуальным.

Глобализационные процессы, активное промышленное освоение Арктического региона крупными предприятиями топливноэнергетического комплекса, а также истощение природных ресурсов приводят к сокращению объемов традиционных видов хозяйствования и неизбежным изменениям в экономическом поведении КМНС. В результате данных процессов, без должного учета интересов коренных малочисленных народов, ухудшились условия жизни и труда аборигенного населения, нарушен экологический баланс территорий, произведено отчуждение земель традиционного природопользования под промыш- ленное использование. Все это приводит к утрате традиционных видов хозяйствования, культуры, родных языков, оказывает крайне неблагоприятное влияние на социальное положение малых народов (Leonov, Shevaryova, 2017). Как следствие, усиливается безработица, снижается интерес к предпринимательской деятельности и внутренняя конкурентоспособность, теряется дух собственности, возрастает экономический пессимизм и апатия, отсутствует готовность планировать собственное финансовое будущее, что крайне негативно сказывается на благополучии коренных малочисленных народов в целом.

Все это поднимает вопрос о необходимости освоения представителями КМНС иных форм экономической деятельности, в том числе адаптированных к современным рыночным условиям и законам, то есть о так называемой трансформации экономического поведения. Для того чтобы экологично осуществить данную трансформацию, необходимо понимание особенностей экономического сознания и поведения, а также того, как связаны эти особенности с ощущением субъективного экономического благополучия у представителей коренных малочисленных народов.

\section{Степень изученности}

Экономическое поведение, наряду с экономическим сознанием, является предметом изучения экономической психоло- 
гии. В то же время экономическое сознание выступает в большей степени как предмет изучения отечественной экономической психологии, внимание же зарубежных психологов сосредоточено в основном на феномене экономического поведения (Lewis, Webley, Furnham, 1995). В целом, практически все исследователи согласны с тем, что два данных феномена тесно взаимосвязаны. Поэтому по характеристикам экономического поведения можно судить об экономическом сознании и наоборот.

В общем, экономическое сознание можно определить как целостную систему отражения объективной экономической действительности, состоящую из различных представленных в психике экономического субъекта элементов, находящихся между собой в закономерных иерархических отношениях. Одно из наиболее ранних определений экономического сознания в отечественной науке дано А.В. Филипповым и С.В. Ковалевым, которые трактуют его как системную составляющую сознания, высший психический уровень отражения экономических отношений общественно развитым человеком (Deineka, 1999).

В числе российских специалистов, активно исследующих данный феномен, следующие авторы: О.С. Дейнека, Т.В. Дробышева, Т.П. Емельянова, А. Л. Журавлев, Н. А. Журавлева, А.И. Китов, А.А. Капустин, А.Б. Купрейченко, С.В. Малахов, И. М. Осипенко, В.П. Позняков, В.Д. Попов, Т.В. Фоломеева, В.П. Фофанов, В. А. Хащенко, Е.В. Шорохова, Е.В. Щедрина и др. Разнообразие взглядов определило существование различных подходов к определению структуры и содержания экономического сознания индивида.

В рамках экономического поведения и сознания наиболее активно изучаются представления об экономических явлениях и о себе в сфере экономики, экономические отношения, стратегии экономического поведения, экономическая социализация, экономические аттитюды, субъективное экономическое благополучие и другие феномены.
Следует зафиксировать ограниченность изучения экономического поведения коренных малочисленных народов. В частности, имеющиеся работы характеризуют проблему в основном с экономической точки зрения (Г.А. Агранат, А.Я. Бакланов, М.К. Бандман, А. Г. Гранберг, Д.А. Додин, В. Н. Лаженцев, Н. П. Лаверов, Г.П. Лузин, П. А. Минакир, Б. А. Райзберг, А. Н. Швецов и др.), что не всегда позволяет увидеть внутренние психологические детерминанты. По мнению О.С. Елькиной, стратегии экономического поведения отражают приоритетную, устойчивую, личностно значимую жизненную направленность индивида. Эта направленность личности представляет собой в первую очередь идентификацию с той или иной областью экономической деятельности (Elkina, 2010).

Поскольку изменения в экономической сфере Российской Арктики критически отражаются на коренных малочисленных народах, сохраняющих идентичность главным образом посредством ведения традиционного хозяйствования, встает вопрос о связи их экономического сознания и поведения с ощущением благополучия и удовлетворенности жизнью.

Субъективное благополучие выступает важной психосоциальной характеристикой личности как субъекта экономической активности (Khashchenko, 2008). Впервые термин «субъективное благополучие» ввел Э. Динер. По мнению автора, благополучие включает когнитивную (интеллектуальную оценку удовлетворенности различными сферами жизни) и эмоциональную стороны самопринятия. Уровень субъективного благополучия не только служит показателем того, насколько человек депрессивен или тревожен, но демонстрирует также, насколько один человек счастливее другого. Э. Динер выделял в структуре субъективного благополучия три основных компонента: удовлетворение, приятные и неприятные эмоции, которые, сочетаясь, формируют уровень субъективного благополучия личности (Diener, Lucas, 1999). Субъективное благополучие в рамках данного исследования отражает отношение и оценку человека 
удовлетворенностью собственной жизнью, что еще раз подчеркивает его актуальность, так как субъективное благополучие коренных малочисленных народов изучено крайне ограниченно (Kuhterina et al., 2020).

Одной из важных составляющих субъективного благополучия является удовлетворенность личным финансовым состоянием, или субъективное экономическое благополучие. В.А. Хащенко рассматривает субъективное экономическое благополучие как «базовый конструкт или (компонент) экономического сознания, который выражает личное отношение человека к своему актуальному и будущему материальному благосостоянию. Основными составляющими его психологического измерения выступают: субъективные переживания человека, его чувственноэмоциональные компоненты, ценностные аспекты отношения к материальной сфере и самому себе, обусловленные объективными обстоятельствами жизнедеятельности и его личными свойствами» (Khashchenko, 2011).

Таким образом, существенные пробелы в научных знаниях по данной тематике позволили сформулировать цель исследования - изучить стратегии экономического поведения коренных малочисленных народов и их влияние на субъективное благополучие данных народов.

\section{Методология}

Для выявления структуры экономических аттитюдов у представителей коренных малочисленных народов в качестве основного методологического инструмента использовался шкальный многофакторный опросник для экспресс-диагностики экономических аттитюдов, разработанный O. С. Дайнекой и Е.В. Забелиной (Deineka, Zabelina, 2018). Данный опросник был выбран в связи с тем, что он позволяет комплексно охарактеризовать поле экономических аттитюдов личности, поскольку в него включены различные сферы экономического поведения: собственника (отношение к деньгам, к собственности, сберегательное и инвестиционное поведение), потребите- ля, предпринимателя и наемного работника. При этом данный опросник достаточно компактен (23 утверждения) и прост в обработке.

Для диагностики субъективного благополучия использовалась Шкала удовлетворенности жизнью Э. Динер в адаптации Д.А. Леонтьева и Е.Н. Осина (Osin, Leont'ev, 2008). Данный опросник положительно зарекомендовал себя на российской выборке в силу простой и однозначной внутренней структуры. Методика «Шкала удовлетворенности жизнью», разработанная Э. Динер в соответствии с его теоретическими положениями, позволяет измерять уровень субъективного благополучия и сравнивать показатели разных людей, демонстрируя, насколько один человек благополучнее, удовлетвореннее, позитивнее другого.

Кроме данных опросников, в исследовании использовалась шкала уровня субъективного дохода А. Фернхам в адаптации O. С. Дейнеки (Deineka, 1999). Респондентам предлагалось оценить уровень своего дохода по 7-балльной шкале, где 1 - свожу концы с концами, а 7 - очень высокий. Данная методика широко применяется в исследованиях по экономической психологии как опосредованный показатель субъективного экономического благополучия человека.

Для выявления структуры экономических аттитюдов были проведен эксплораторный факторный анализ (по методу главных компонент с варимакс-вращением). Для выявления влияния стратегий экономического поведения на субъективное благополучие использовался регрессионный анализ (пошаговый метод). Для обработки полученных данных был задействован статистический пакет SPSS24.0.

В исследовании принимали участие 213 представителей коренных малочисленных народов в возрасте от 15 до 73 лет (59 \% женщин и $41 \%$ мужчин), проживающих в различных субъектах Арктической зоны Российской Федерации: ненцы (ЯмалоНенецкий автономный округ, Ненецкий автономный округ) - 78 человек (63 \% жен- 
щин и 37 \% мужчины, средний возраст 30,7 лет), ханты (Ямало-Ненецкий автономный округ) - 5 человек (60\% женщины и $40 \%$ мужчины, средний возраст 16 лет), долганы (Красноярский край) - 32 человека (78 \% женщины и $22 \%$ мужчины, средний возраст 32,3 лет), ительмены (Камчатский край) - 2 человека (100\% мужчины, средний возраст 21 год), коряки (Камчатский край) - 8 человек (37,5 \% женщины и 62, 5 \% мужчины, средний возраст 38,5 лет), нивхи (Сахалинская область) - 25 человек (56 \% женщин и $44 \%$ мужчин, средний возраст $36,6)$, эвены (Красноярский край) - 31 человек (32\% женщин и 68 \% мужчин, средний возраст 38,1), чукчи (Чукотский автономный округ) - 25 человек (64 \% женщин и $36 \%$ мужчин, средний возраст 36,5 лет), эскимосы (Чукотский автономный округ) 7 человек (86 \% женщины и 14 \% мужчин, средний возраст 34,3 лет).

Анкеты предлагали респондентам для заполнения на бумажном носителе, при этом у респондентов была возможность задавать вопросы в ходе их заполнения.

\section{Обсуждение}

На первом этапе исследования у представителей коренных малочисленных народов диагностировались экономические аттитюды. Затем проводился факторный анализ экономических аттитюдов с целью выделения наиболее «объемных» компонентов экономического сознания, определяющих стратегии поведения в экономической сфере. Результаты факторного анализа представлены в табл. 1.

В ходе факторного анализа было выделено четыре фактора, которые могут быть интерпретированы как различные стратегии экономического поведения КМНС.

Первый фактор, показавший в ходе факторного анализа наибольший вес, отражает, вероятно, наиболее типичную стратегию экономического поведения КМНС - стратегию сбережений на основе финансовых знаний и активности. Фактор объединяет такие экономические аттитюды, как уверенность в будущем благодаря сбережениям, финансовая грамотность, потребительское удовлетворение, стремление к сбережению, финансовый оптимизм, активность и рациональность в банковской сфере, потребительская активность, готовность инвестировать, познавательная экономическая активность, рациональность покупок.

«Сердцевина» первого фактора склонность создавать сбережения, которая поддерживается активностью экономического поведения в разных сферах (покупки, банковские операции, стремление к финансовым знаниям) и финансовой грамотностью. Кроме того, связанными аттитюдами здесь являются такие позитивные феномены в экономической сфере, как финансовый оптимизм, уверенность в будущем, готовность инвестировать, потребительское удовлетворение, что позволяет предполагать связь данной стратегии с психологическим благополучием респондентов.

Содержание второго фактора демонстрирует приоритет материальных ценностей у части выборки, а также стремление респондентов занимать высокий финансовый статус. Данный фактор был обозначен как стратегия высоких финансовых достижений. Данная стратегия объединяет выраженные экономические амбиции, высокую значимость финансового статуса, ценность самостоятельных экономических достижений, приоритет заработка над призванием и активность в сфере недвижимости.

Формирование такой стратегии в экономическом сознании коренных малочисленных народов вызывает опасения с точки зрения того, что высокие экономические амбиции не находят подкрепления в конкретных действиях (отсутствие плана, знаний, намерений и пр.). Можно предположить, что эта стратегия носит скорее декларативный характер, не подкрепленный конкретными намерениями, и в случае недостижения желаемых финансовых целей может порождать разочарование, обиду на общество и деструктивные формы экономического поведения (рисковое и игровое поведение).

Третий фактор образован совокупностью следующих аттитюдов: осознание 
Таблица 1. Результаты факторного анализа экономических аттитюдов Table 1. Results of factor analysis of economic attitudes

\begin{tabular}{|c|c|c|c|c|}
\hline & \multicolumn{4}{|c|}{ Факторы } \\
\hline & 1 & 2 & 3 & 4 \\
\hline Уверенность в будущем благодаря сбережениям &, 800 & & & \\
\hline Финансовая грамотность & ,771 & & & \\
\hline Потребительское удовлетворение & ,742 & & & \\
\hline Стремление к сбережению & 630 & & & \\
\hline Финансовый оптимизм & ,565 & & & \\
\hline Активность, рациональность в банковской сфере & ,561 & & & \\
\hline Потребительская активность & ,551 & & & \\
\hline Готовность инвестировать & ,525 & & & \\
\hline Познавательная экономическая активность & ,479 & & & \\
\hline Рациональность покупок & ,445 & & ,405 & \\
\hline Экономические амбиции & & 665 & & \\
\hline Значимость финансового статуса & & ,643 & & \\
\hline Ценность самостоятельных экономических достижений & & ,583 & ,416 & \\
\hline Приоритет заработка призванию & & ,556 & & \\
\hline Активность в сфере недвижимости & & ,412 & & \\
\hline Осознание потребительской иррациональности & & &, 768 & \\
\hline Инвестиционная неграмотность & & & ,707 & \\
\hline Избегание долгов & & & ,436 & \\
\hline Социальная ответственность богатства & & & ,412 & \\
\hline Негатив к предпринимателям & & & & ,758 \\
\hline Приоритет заработка над здоровьем & & & & ,670 \\
\hline Предпочтение покупки в кредит & & & & 479 \\
\hline Недоверие к банкам, иррациональность & & & & \\
\hline Доля объяснимой дисперсии,\% & 25,17 & 8,1 & 6,9 & 6,7 \\
\hline
\end{tabular}

потребительской иррациональности, инвестиционная неграмотность, избегание долгов, социальная ответственность богатства, рациональность покупок, ценность самостоятельных экономических достижений. Данный фактор может отражать ограничительную стратегию в экономической сфере, основанную на рациональности и самостоятельности. Суть данной стратегии заключается в ориентации экономического сознания респондентов на уменьшение трат в экономической жизни, рациональность в принятии покупательских решений, в отсутствии демонстративного потребления и вещизма.
Данная стратегия, с одной стороны, базируется на уверенности в своих силах в достижении экономических целей, с другой - подкрепляется отсутствием знаний в области инвестирования средств.

Четвертый фактор включает в себя негативное отношение к предпринимателям, приоритет заработка над здоровьем и предпочтение кредитам. Данный фактор может быть назван «Стратегия наемной работы». Данная стратегия предполагает «жизнь на зарплату», при этом деньги становятся более значимыми в системе жизненных ценностей, чем даже здоровье. В сознании респондентов единственным 
способом реализовать желания в экономической сфере становится кредит. Таким образом, эта группа респондентов может попасть в «ловушку бесконечных долгов» и нехватки денег, что подразумевает негативные психологические переживания. Респонденты могут пытаться оправдывать сложившуюся ситуацию тем, что они «не способны лгать и изворачиваться, как предприниматели».

Поскольку выделенные в ходе факторного анализа стратегии экономического поведения несут разную эмоциональную нагрузку, на следующем этапе проверялась гипотеза о том, как обозначенные стратегии связаны с субъективным благополучием коренных малочисленных народов.

Регрессионный анализ (табл. 2), в котором независимыми переменными выступили стратегии экономического поведения, а зависимой переменной - субъективное благополучие, показал, что только стратегия сбережений на основе знаний и активности как сама по себе, так и в сочетании со стратегией ограничительного экономического поведения вносит вклад в повышение уровня субъективного благополучия КМHC.

Поскольку удовлетворенность жизнью и удовлетворенность доходом представляют разные, хотя и взаимосвязанные кон- структы (Khashchenko, 2011; Zabelina et al., 2020), следующим шагом была проверка гипотезы о взаимосвязи стратегий экономического поведения и субъективного экономического благополучия (субъективного уровня дохода). Регрессионный анализ показал результаты, в целом согласующиеся с данными, полученными на предыдущем этапе (табл. 3).

Стратегия сбережений на основе знаний и активности по-прежнему вносит наибольший вклад в формирование субъективного экономического благополучия коренных малочисленных народов. Ограничительная стратегия также, хотя и в незначительной степени, способствует достижению субъективного экономического благополучия. При этом стратегия высоких финансовых достижений, основанная на экономических амбициях, но не подкрепленная конкретными намерениями и планами, снижает уровень субъективно воспринимаемого дохода. Скорее всего, данная стратегия является защитной реакцией на неудовлетворённость сегодняшней финансовой ситуацией и желанием ее изменить.

\section{Заключение}

Таким образом, в ходе исследования было выявлено несколько укрупненных

Таблица 2. Результаты регрессионного анализа: влияние стратегий экономического поведения на субъективное благополучие (удовлетворенность жизнью) КМНС

Table 2. Regression analysis results: influence of economic behavior strategies on the subjective well-being (life satisfaction) of the indigenous small-numbered peoples of the North

\begin{tabular}{|c|c|c|c|c|c|c|}
\hline \multirow{2}{*}{\multicolumn{2}{|c|}{$\begin{array}{l}\text { Модель } \\
\text { В }\end{array}$}} & \multicolumn{2}{|c|}{$\begin{array}{c}\text { Нестандартизованные } \\
\text { коэффициенты }\end{array}$} & \multirow[t]{2}{*}{$\begin{array}{c}\text { Стандартизованные } \\
\text { коэффициенты }\end{array}$} & \multirow{2}{*}{$\mathrm{T}$} & \multirow{2}{*}{$\mathrm{p}$} \\
\hline & & $\begin{array}{c}\text { Стандартная } \\
\text { ошибка }\end{array}$ & Бета & & & \\
\hline \multirow[t]{2}{*}{1} & (Константа) & 4,145 &, 080 & & 51,918 &, 000 \\
\hline & $\begin{array}{l}\text { Сбережения на основе знаний } \\
\text { и активности }\end{array}$ & 694 &, 080 & ,493 & 8,658 &, 000 \\
\hline \multirow[t]{3}{*}{2} & (Константа) & 4,145 & ,079 & & 52,753 &, 000 \\
\hline & $\begin{array}{l}\text { Сбережения на основе знаний } \\
\text { и активности }\end{array}$ &, 694 & ,079 & ,493 & 8,797 &, 000 \\
\hline & Ограничительная стратегия & ,231 & 079 & 164 & 2,924 & ,004 \\
\hline
\end{tabular}

Примечание. Зависимая переменная: субъективное благополучие.

$$
-804-
$$


Таблица 3. Результаты регрессионного анализа:

влияние стратегий экономического поведения на субъективный уровень дохода КМНС

Table 3. Regression analysis results: influence of economic behavior strategies on the subjective income level of the indigenous small-numbered peoples of the North

\begin{tabular}{|c|c|c|c|c|c|c|}
\hline \multirow{2}{*}{\multicolumn{2}{|c|}{$\begin{array}{c}\text { Модель } \\
\text { В }\end{array}$}} & \multicolumn{2}{|c|}{$\begin{array}{c}\text { Нестандартизованные } \\
\text { коэффициенты }\end{array}$} & \multirow{3}{*}{\begin{tabular}{|c|}
$\begin{array}{c}\text { Стандартизованные } \\
\text { коэффициенты }\end{array}$ \\
\\
\end{tabular}} & \multirow{3}{*}{\begin{tabular}{|c|}
$\mathrm{T}$ \\
47,653 \\
\end{tabular}} & \multirow{3}{*}{$\begin{array}{c}\mathrm{p} \\
, 000\end{array}$} \\
\hline & & \multirow{2}{*}{$\begin{array}{c}\begin{array}{c}\text { Стандартная } \\
\text { ошибка }\end{array} \\
3,258\end{array}$} & \multirow{2}{*}{$\begin{array}{c}\text { Бета } \\
, 068\end{array}$} & & & \\
\hline 1 & (Константа) & & & & & \\
\hline & $\begin{array}{l}\text { Сбережения на основе } \\
\text { знаний и активности }\end{array}$ &, 358 &, 069 &, 324 & 5,219 &, 000 \\
\hline \multirow[t]{3}{*}{2} & (Константа) & 3,258 & ,068 & & 48,244 & 000 \\
\hline & $\begin{array}{l}\text { Сбережения на основе } \\
\text { знаний и активности }\end{array}$ &, 358 &, 068 &, 324 & 5,284 &, 000 \\
\hline & $\begin{array}{l}\text { Самостоятельные } \\
\text { финансовые достижения }\end{array}$ &,- 177 &, 068 &,- 160 & $-2,610$ & 010 \\
\hline \multirow[t]{4}{*}{3} & (Константа) & 3,258 & ,067 & & 48,645 &, 000 \\
\hline & $\begin{array}{l}\text { Сбережения на основе } \\
\text { знаний и активности }\end{array}$ &, 358 &, 067 &, 324 & 5,328 &, 000 \\
\hline & \begin{tabular}{|l} 
Самостоятельные \\
финансовые достижения
\end{tabular} &,- 177 & ,067 &,- 160 & $-2,632$ & ,009 \\
\hline & Ограничительная стратегия & ,149 & ,067 & ,134 & 2,208 & 028 \\
\hline
\end{tabular}

Примечание. Зависимая переменная: субъективный доход.

характеристик экономического сознания у представителей коренных малочисленных народов, которые с высокой вероятностью определяют типичные стратегии их экономического поведения. Следовательно, особенностью экономического поведения КМНС можно считать преобладание практически во всех стратегиях ориентации на сбережения и рациональность. При этом в сочетании с экономической активностью и финансовыми знаниями данная стратегия ведет к повышению удовлетворенностью жизнью и уровня субъективного экономического благополучия.

Таким образом, полученные результаты не только свидетельствуют о необходимости повышения финансовой грамотности и стимулирования экономической активности у представителей коренных малочисленных народов Севера, Сибири и Дальнего Востока Российской Федерации в целом, но и ставят вопрос о разработке адаптированных под их образ жизни уже действующих программ в данной сфере.

\section{Список литературы}

Брега, Г.В. (2018). Этнические особенности экономического поведения. «Прометей», $171 \mathrm{c.}$

Борисов, В.Н., Почукаева, О.В. (2016). Взаимосвязи факторов развития Арктической зоны РФ // Проблемы прогнозирования, 2, 59-68.

Дейнека, О.С. (1999). Экономическая психология: сочиально-политические проблемы. СПб, 260 с.

Дейнека, О.С. (2011). Экономическое сознание: феноменология, структура и потенциал развития // Культура и экономическое поведение, 118-148.

Дейнека, О.С., Забелина, Е.В. (2018). Результаты разработки шкального многофакторного опросника для экспресс-диагностики экономических аттитюдов // Психологические исследования, 11(58), 9. Режим доступа: http://psystudy.ru 
Деттер, Г.Ф. (2019). Экономическое поведение коренных малочисленных народов Севера России: постановка проблем // Вестник Челябинского государственного университета, 9(431), 32-42.

Дрегало, А.А., Ульяновский, В.И. (2016). Инерционные процессы в общественном сознании Северного региона // Материаль международной научно-практической конференции «Мониторинг и оценка развития территорий Арктической зоны». Архангельск, 304-306.

Елькина, О.С. (2010). Управление стратегиями экономического поведения работников на рынке труда. Омск, 330 с.

Забелина, Е.В., Курносова, С.А. (2018). Особенности экономического сознания представителей коренных малочисленных народов Арктической зоны: результаты пилотного исследования молодежи // Петербургский психологический журнал, 23. Режим доступа: http://ppj.spbu.ru/index. php/psy/article/view/203

Забелина, Е.В., Курносова, С.А., Телицына, А.Ю., Щукина, К.Е. (2019). Взаимосвязь экономических аттитюдов и жизненных ценностей у представителей коренных малочисленных народов Российской Арктики (на материале исследования ненцев) // Вестник МГОУ, 3, 105-115.

Копцева, Н.П., Сергеева, Н.А., Ермаков, Т.К. (2018). Современные способы этнической самоидентификации на материале анализа эвенкийской этнокультурной группы // Специфика этнических миграционных прочессов на территории Центральной Сибири в XX-XXI веках: опыт и перспективы. Красноярск, 195-198.

Кухтерина, Г.В., Соловьева, Е.А., Федина, Л.В., Муравьева, М.В. (2020). Субъективное благополучие старшеклассников, принадлежащих к коренным малочисленным народам Севера как основа готовности к выбору профессии // Образование и наука, 2 (5), 111-131.

Лескин, В.Н., Порфирьев, Б.Н. (2015). Научный и институциональный потенциал комплексного развития российской Арктики в средне- и долгосрочной перспективе // Проблемы прогнозирования, $6,58-66$.

Леонов, С.Н., Шеварева, Я.С. (2017). Проблемы и перспективы традиционных видов хозяйственной деятельности коренных малочисленных народов Севера и Дальнего Востока // Регионалистика, 4 (2), 26-44.

Литвина, С.А., Богомаз, С.А. (2014). Индивидуальные достоинства как предикторы удовлетворенности человека своей жизнью // Сибирский психологический журнал, 211-219.

Осин, Е.Н., Леонтьев, Д.А. (2008). Апробащия русскоязычных версий двух шкал экспресс-оценки субъективного благополучия. Режим доступа: http://www.isras.ru/abstract_bank/1210190841.pdf

Осипова, О.В. (2014). Изменение жизненных стратегий и экономического поведения молодежи Арктики // Арктика и Север, 14.

Павленко, В.И., Дрегало, А.А., Ульяновский, В.И., Куценко, С.Ю., Малинина, К.О., Балицкая, С.М. (2017). Методологические особенности социально-экономических исследований Арктической зоны Российской Федерации // Известия Коми научного иентра УрО РАН, 1(29).

Российская Арктика: коренные народы и промышленное освоение (2016). Под ред. В. А. Тишкова. Москва, $272 \mathrm{c}$.

Хащенко, В.А. (2011). Субъективное экономическое благополучие и его измерение: построение опросника и его валидизация // Экспериментальная психология, 4(1), 106-127.

Хащенко, В.А. (2005). Экономико-психологическая модель субъективного экономического благополучия // Психологический журнал, 26(4), 5-19.

Хащенко, В.А. (2008). Структура субъективного экономического благополучия в зависимости от его уровня // Вестник Российского университета дружбы народов. Серия: Психология и педагогика, 2, 29-45.

Харючи, Г.П., Петрова, В.Р. (2014). Ненцы в истории Ямала // Научный вестник Ямало-Ненецкого автономного округа, 3 (84), 55-59.

Шварц, Ш., Бутенко, Т.П., Седова, Д.С., Липатова, А.С. (2012). Уточненная теория базовых индивидуальных ценностей: применение в России // Психология. Журнал высшей школь экономики, 9(1), 43-70. 
Этнонациональные процессы в Арктике: тенденции, проблемы и перспективы: монография (2017). Архангельск, 325 с.

\section{References}

Brega, G. V. Etnicheskie osobennosti ekonomicheskogo povedeniia [Ethnic features of economic behavior]. «Prometei», 2018, $171 \mathrm{p}$.

Borisov, V.N., Pochukaeva, O.V. (2016). Vzaimosviazi faktorov razvitiia Arkticheskoi zony RF [Interrelations of factors of development of the Arctic zone of the Russian Federation]. In Problemy prognozirovaniia, 2, 59-68.

Deineka, O.S. (1999). Ekonomicheskaia psihologiia: sotsial'no-politicheskie problemy [Economic psychology: socio-political problems]. Saint-Petersburg, SPbGU.

Deineka, O.S. (2011). Ekonomicheskoe soznanie: fenomenologiia, struktura i potenzial razvitiia [Economic consciousness: phenomenology, structure and potential of development]. In Kul'tura i ekonomicheskoe povedenie: sbornik statei. Moskva, Maks Press, 118-148.

Deineka, O.S., Zabelina, E.V. (2018). Rezuitaty razrabotki shkal'nogo mnogofaktornogo oprosnika dlia ekspress-diagnostiki ekonomicheskikh attitiudov [Results of development of the school multiple-factor questionnaire for express diagnostics of economic attitudes]. In Psikhologicheskie issledovaniia, 11 (58), 9 , available at: http://psystudy.ru

Detter, G.F. (2019). Ekonomicheskoe povedenie korennyh malochislennyh narodov Severa Rossii: postanovka problem [Economic behavior of the indigenous peoples of the Russian north: statement of the problem]. In Vestnik CHelyabinskogo gosudarstvennogo universiteta, 9 (431), 32-42.

Diener, E., Lucas, R.E. (1999). Personality and subjective well-being // Well-being: The foundations of hedonic psychology. N.Y., 213-229.

Dregalo, A.A., Ul'ianovskii, V.I. (2016). Inertsionnye protsessy v obshchestvennom soznanii Severnogo regiona Rossii [Inertial processes in public consciousness of the Northern region of Russia]. In Materialy mezhdunarodnoi nauchno-prakticheskoi konferentsii «Monitoring I otsenka razvitiya territorii Arkticheskoi zony». Arkhangel'sk, «KIRA», 304-306.

Elkina, O.S. (2010). Upravlenie strategiyami ekonomicheskogo povedeniya rabotnikov na rynke truda. Omsk: Izdatel'stvo Omskij institut (filial) RGTEU. 330 p.

Etnonacional'nye processy $v$ Arktike: tendencii, problemy i perspektivy: monografiya [Ethnonational processes in the Arctic: trends, problems and prospects] (2017). Arhangel'sk: SAFU, 325 p.

Furnham, A. (1996). Attitudinal correlates and demographic predictors of monetary beliefs and behaviors. In Journal of Organizational Behavior, 17 (4), 375-388.

Furnham, A. (2014). The new psychology of money. London: Routledge.

Khashchenko, V.A. (2011). Sub"ektivnoe ekonomicheskoe blagopoluchie i ego izmerenie: postroenie oprosnika i ego validizaciya [Subjective economic well-being and its measurement: constructing and validating a questionnaire]. In Eksperimental'naya psihologiya, 4 (1), 106-127.

Khashchenko, V.A. (2005). Ekonomiko-psihologicheskaya model' sub»ektivnogo ekonomicheskogo blagopoluchiya [Economic-psychological model of subjective economic well-being]. In Psikhologicheskii zhurnal, 26 (4), 5-19.

Khashchenko, V.A. (2008) Struktura sub"'ektivnogo ekonomicheskogo blagopoluchiya v zavisimosti ot ego urovnya. In Vestnik Rossijskogo universiteta druzhby narodov. Seriya: Psihologiya i pedagogika, 2 , 29-45.

Khariuchi, G.P., Petrova, V.P. (2014). Nentsy v istorii Iamala [Nenets in the history of Yamal]. In nauchnyi vestnik Iamalo-Nenetskogo avtonomnogo okruga, 3(84), 55-59.

Koptseva, N.P., Sergeeva, N.A., Ermakov, T.K. (2018). Sovremennye sposoby etnicheskoy samoidentifikatsii na material analiza evenkiiskoi etnokul'turnoi gryppy [Modern ways of ethnic self-identification on material of the analysis of the Evenki ethnocultural group]. In Spetsifika etnicheskikh migratsionnykh protsessov na territorii tsentralnoi Sibiri v XX-XXI vekah: opyt I perspektivy. Krasnoiarsk, Sibirskii Federal'nyi universitet, 195-198. 
Kuhterina, G.V., Solov’eva, E.A., Fedina, L.V., Murav'eva, M.V. (2020) Sub»ektivnoe blagopoluchie starsheklassnikov, prinadlezhashchih k korennym malochislennym narodam Severa, kak osnova k gotovnosti k vyboru professii. In Obrazovanie i nauka, 2 (5), 111-131.

Lewis, A., Webley, P., Furnham, A. (1995). The new economic mind: the social psychology of economic behavior. Hemel Hempstead, Harvester/Wheatsheaf, 332 p.

Leksin, V.N., Porfir'ev, B.N. (2015). Nauchnyi I institutsionalnyi potentsial kompleksnogo razvitiia rossiiskoi Arktiki v sredne- i dolgosrochnoi perspective [Scientific and institutional potential of complex development of the Russian Arctic in the average and long term]. In Problemy prognozirovaniia, 6, 58-66.

Leonov, S.N., Shevaryova, Ya.S. (2017). Problemy i perspektivy razvitiya tradicionnyh vidov hozyajstvennoj deyatel'nosti korennyh malochislennyh narodov Severa Dal'nego Vostoka. In Regionalistika, 4 (2), 26-44.

Litvina, S.A., Bogomaz, S.A. (2014). Individual'nye dostoinstva kak prediktory udovletvorennosti cheloveka svoej zhizn'yu [Personal virtues as predictors of life satisfaction]. In Sibirskij psihologicheskij zhurnal, 211-219.

Luzan, V.S. (2018). Practical Aspects of Cultural Policy in Ethnic Administrative Territorial Units // in Facets of Culture in the Age of Social Transition. In Proceedings of the All-Russian Research Conference with International Participation, KnE Engineering, 99-103.

Luzan, V.S., Koptseva, N.P., Zabelina, E.V., Kurnosova, S.A., Trushina, I.A. (2019). The Structure of Economic Attitudes of the Youth - Representatives of the Indigenous Small-Numbered Peoples of the Arctic Zone of the Russian Federation: Results of a Pilot Study. In Journal of Siberian Federal University. Humanities \& Social Sciences, 12 (6), 1146-1162.

Osin, E.N., Leont'ev, D.A. (2008). Aprobaciya russkoyazychnyh versij dvuh shkal ekspress-ocenki sub"ektivnogo blagopoluchiya [Testing Russian-language versions of two scales of rapid assessment of subjective well-being]. M.: Institut sociologii RAN, Rossijskoe obshchestvo sociologov.

Osipova, O.V. (2014). Izmenenie zhiznenykh strategii I ekonomicheskogo povedeniia molodezhi Arktiki [Change of vital strategy and economic behavior of youth of the Arctic]. In Arktika I sever, 14.

Pavlenko, V.I., Dregalo, A.A., Ul'ianovskii, V.I., Kutsenko, S. Iu., Malinina, K.O., Balitskaia, S.M. (2017). Metodologicheskie osobennosti sotsial'no-ekonomicheskikh issledovanii Arkticheskoi zony Rosiiskoi Federatsi [Methodological features of social and economic researches of the Arctic zone of the Russian Federation]. In Izvestiia Komi nauchnogo tsentra UrO RAN, 1 (29).

Rossiiskaia Arktika: korennye narody I promyshlennoe osvoenie [Russian Arctic: indigenous people and industrial development] (2016). Pod red. V. A. Tishkova. Moskva, Sankt-Peterburg, NestorIstoriia, $272 \mathrm{p}$.

Schwartz, Sh., Butenko, T.P., Sedova, D.S. (2012). Utochnennaya teoriya bazovyh individual'nyh cennostej: primenenie v Rossii [Theory of Basic Personal Values: Validation in Russia]. In Psihologiya. Zhurnal Vysshej shkoly ekonomiki, 9 (1), 43-70.

Shvarts, Sh., Butenko, T.P, Sedova, D.S, Lipatova, A.S. (2012). A refined theory of basic individual values: application in Russia, Psychology. In Journal of the Higher School of Economics, 9 (1), 43-70.

Zabelina, E., Deyneka, O., Tsiring, D. (2019). Entrepreneurial attitudes in the structure of students' economic minds. In International Journal of Entrepreneurial Behavior \& Research, available at: https://oi. org/10.1108/IJEBR-04-2018-0224

Zabelina, E.V., Kurnosova, S.A. (2018). Osobennosty ekonomicheskogo soznaniia predstavitelei korennykh malochislennykh narodov Arkticheskoy zony: rezuitaty pilotnogo issledovaniia molodezhi [Features of economic consciousness of representatives of indigenous ethnic groups of the Arctic zone: results of a pilot research of youth]. In Peterburgskii psikhologicheskii zhurnal, 23, available at: http://ppj.spbu.ru/ index.php/psy/article/view/203

Zabelina, E.V., Kurnosova, S.A., Telicina, A. Yu., Shchukina, K.E. (2019). Vzaimosvya' ekonomicheskih attityudov i zhiznennyh cennostej u predstavitelej korennyh malochislennyh narodov Rossijskoj Arktiki (na materiale issledovaniya nencev) [Interrelation between economic attitudes and

$$
-808-
$$


life values of the small indigenous peoples of the Russian Arctic (on the nenets sample)]. In Vestnik $M G O U, 3,105-115$.

Zabelina, E.V., Kurnosova, S.A., Trushina, I.A., Koptseva, N.P., Luzan, V.S. (2020). Life Values and Subjective Well-being of the Indigenous Small-Numbered Peoples of the Arctic Zone (Based on the Example of the Nenets). In Journal of Siberian Federal University. Humanities \& Social Sciences, 13 (6), 997-1006. 